\title{
Produtividade, demanda e gasto com arrendamentos na orizicultura gaúcha
}

\author{
Productivity, demand and price of leases in Rio Grande do Sul rice production
}

Rogério Boueri Miranda ${ }^{1 \S} \mathbb{D}$; Flávio Carlos Dalchiavon ${ }^{2} \mathbb{D}$

Received: nov. 01, 2021

Accepted: jan. 05, 2022

${ }^{1}$ Instituto de Ensino, Pesquisa e Desenvolvimento IDP - Brasília, DF, Brasil.

${ }^{2}$ Instituto Federal de Educação, Ciência e Tecnologia de Mato Grosso - IFMT - Departamento de Agronomia - Campus Avançado Diamantino Diamantino MT, Brasil.

${ }^{\S}$ Autor correspondente <rogerio.miranda@idp.edu.br>

\section{(c) (i)}

Este é um artigo publicado em acesso aberto (Open Access) sob a licença Creative Commons Attribution, que permite uso, distribuição e reprodução em qualquer meio, sem restrições desde que o trabalho original seja corretamente citado.
Resumo: O objetivo deste artigo é conciliar fatos aparentemente contraditórios em relação à orizicultura gaúcha: se, por um lado, os preços internos do arroz apresentam declínio significativo nas últimas décadas, por outro, os gastos com arrendamentos nas regiões produtoras de arroz irrigado no Rio Grande do Sul têm crescido substancialmente. Com o intuito de elucidar essa dicotomia, utilizou-se dados dos Censos Agropecuários de 2006 e de 2017 e da Pesquisa Agropecuária Municipal de 2006 a 2018, ambos produzidos pelo Instituto Brasileiro de Geografia e Estatística (IBGE), para se avaliar a hipótese de que o crescimento heterogêneo da produtividade na cultura do arroz irrigado, nas regiões produtoras do Rio Grande do Sul, causou concentração da demanda por arrendamentos nas áreas de maior incremento de produtividade. Para tanto, realizou-se a análise econométrica, na qual a variação nos dispêndios com arrendamento foi utilizada como variável endógena, e as variações nas produtividades do arroz, do milho e da soja como variáveis explicativas. Também foram utilizadas variáveis de controle, com o intuito de isolar a influência das variáveis de interesse. Detectou-se impacto significativo do aumento da produtividade do arroz sobre o aumento dos dispêndios com arrendamentos nas regiões orizícolas gaúchas, no entanto, tais impactos não foram significativos sobre o crescimento da produtividade da soja ou do milho.

Palavras-chave: custos de produção; produtividade agrícola; uso da terra.

\begin{abstract}
The aim of this article is to reconcile apparently contradictory facts about rice production at Rio Grande do Sul. On the one hand, rice domestic prices have shown significant decline along last decades, but on the other hand, lease expenditures have grown substantially at irrigated rice producer regions. With the purpose of shed some light on this dichotomy, data from the Agricultural Censuses, from 2006 and 2017, and the Municipal Agricultural Research, from 2006 to 2018, both produced by the Brazilian Institute of Geography and Statistics (Instituto Brasileiro de Geografia e Estatística - IBGE), were used to assess the hypothesis that the heterogeneous growth in productivity in irrigated rice cultivation in producing regions of Rio Grande do Sul caused concentration of demand for leases in the areas of greatest productivity increase. An econometric analysis was performed, in which the variation in expenditure on leasing was used as endogenous variable and the variations in the productivity of rice, corn and soybeans as explanatory variables. Control variables were also employed to isolate the influence of the variables of interest. A significant impact of increase in rice productivity was detected on the increase in spending on leases in the rice producing regions of Rio Grande do Sul, however, such impacts were not found significant in the case of growth in productivity of soybeans or corn.
\end{abstract}

Keywords: production costs; agricultural productivity; land use. 


\section{Introdução}

A evolução da cultura do arroz no Rio Grande do Sul está inserida no desenvolvimento agrário peculiar ocorrido na região e, de certa forma, tipifica-o. Em contraposição ao modelo agroexportador, no qual as produções com maior valor agregado eram aquelas voltadas à exportação, a agropecuária gaúcha concentrou seus esforços na produção de bens de consumo internos, regional ou nacionalmente.

A abolição da escravatura e a chegada maciça de imigrantes - que causaram influxo intenso aos centros urbanos -, bem como a imposição de tarifas de importação sobre vários produtos, inclusive o arroz, tiveram efeito positivo sobre a produção ${ }^{[1]}$. Além disso, as condições agronômicas, incluindo o tipo de terra, de relevo, e de regimes fluviais, são extremamente favoráveis ao cultivo do arroz ${ }^{[2]}$.

O mais importante, talvez, para o florescimento da orizicultura gaúcha tenha sido o contexto social na qual foi germinada. A estrutura fundiária menos concentrada e a imigração favoreceram a divisão do trabalho, o trabalho assalariado, o desenvolvimento de indústria de bens de produção e a separação entre trabalho e propriedade da terra ${ }^{[3]}$. Por fim, a facilidade de beneficiamento e armazenagem do arroz vis-à-vis o milho e a mandioca favoreceram a exportação do produto às demais províncias, mesmo levando-se em conta a infraestrutura portuária precária.

Esses fatores levaram ao rápido avanço na produtividade agrícola do arroz, com taxa média anual de $1,4 \%$ entre as safras de 1921/1922 e de 2019/2020, segundo Instituto Rio Grandense do Arroz ${ }^{[4]}$. No entanto, essa tendência secular de incremento da produtividade não impediu que os produtores gaúchos enfrentassem dificuldades, particularmente, a partir da década passada. Essas dificuldades resultaram, ao longo dos anos, em alto nível de endividamento dos produtores de arroz.

O crescimento dos custos com ritmo superior à ascensão dos preços é frequentemente apontado como uma das causas da deterioração financeira de muitos produtores. A Companhia Nacional de Abastecimento (CONAB) ${ }^{[5]}$ aponta para crescimento de até $99,2 \%$ nos custos variáveis de produção entre as safras $2007 / 2008$ e 2016/2017, embora haja exceções a essa tendência ${ }^{[6]}$. O poder de mercado dos beneficiadores e das grandes cadeias de varejo causam perdas de margens aos agricultores, reduzindo, assim, sua capacidade de pagamento ${ }^{[7]}$. A heterogeneidade tributária com os parceiros do Mercosul, por sua vez, também leva à perda de competitividade da produção nacional[8],[9].

A queda da demanda doméstica exerce papel preponderante na perda de faturamento dos produtores gaúchos. O consumo per capita de arroz no Brasil chegou a atingir $76 \mathrm{~kg}^{\text {ano }}{ }^{-1}$, mas, atualmente, está na faixa de $34 \mathrm{~kg} \mathrm{ano}^{-1}$. Em termos absolutos, a média decenal do consumo total de arroz no Brasil foi de 8,64 milhões de toneladas nos anos 1990, contra 8,55 milhões de toneladas na última década, segundo o United States Department of Agriculture (USDA) ${ }^{[10]}$. Essa estagnação refletiu-se, de maneira direta, nos preços internos de venda. Segundo o IRGA ${ }^{[11]}$, a queda dos preços reais do arroz no mercado interno entre 1975 e 2019 foi de 75,1\%, muito embora o preço em dólares do produto tenha se apreciado em 12,3\%.

No entanto, os preços das terras têm subido de forma acelerada nas regiões produtoras de arroz irrigado, assim como os arrendamentos. Entre os anos de 2006 e 2017, esses dispêndios nas regiões produtoras cresceram $259 \%$ nominalmente e $133 \%$ em valores reais, conforme dados do Instituto Brasileiro de Geografia e Estatística (IBGE) ${ }^{[12],[13]}$. Esses fatos levam, quando conjuntamente considerados, ao aparente paradoxo: de um lado, tem-se cenário de estagnação de consumo, queda acentuada de preços e dificuldades financeiras de parte dos produtores; de outro, elevação dos arrendamentos nas áreas orizícolas.

Assim sendo, o principal objetivo deste trabalho é apresentar um conjunto de fatos para esclarecer a aparente contradição entre a queda de preços e rentabilidade e o aumento dos custos de arrendamento. A hipótese central é a de que os aumentos de produtividade ocorridos nas regiões produtoras de arroz irrigado, assim como a estagnação da demanda, levaram ao excesso de oferta, que tem, sistematicamente, pressionado os preços do arroz. Essa situação leva, simultaneamente, a dificuldades financeiras a produtores cujas lavouras estão localizadas nas regiões de menor aumento na produtividade e, também, as elevações expressivas nos arrendamentos daquelas regiões de elevação mais rápida da produtividade.

\section{Material e Métodos}

Nesta seção foram descritos os principais elementos estatísticos para a construção do argumento central do trabalho. Em primeiro lugar, delimitou-se as regiões produtoras de arroz irrigado do Rio Grande do Sul e avaliou-se o crescimento da produtividade, não só desse produto, mas também de outros grãos cultivados na região (especificamente, soja e milho), no período entre as safras 2005/2006 e 2016/2017. A escolha do período deu-se devido à disponibilidade de dados dos Censos Agropecuários. Em seguida, descreveu-se a evolução da demanda nacional por arroz, com o intuito de demonstrar que essa variável não acompanha o crescimento da produtividade do grão. 
Esse descompasso entre o aumento da produtividade do arroz e a estagnação da demanda por esse grão produz pressão baixista sobre os preços, que também é avaliada nesta seção. Os gastos com arrendamentos nas regiões produtoras também são descritos, com o objetivo de mostrar que, a despeito da queda do preço do arroz, tem ocorrido crescimento nessa variável.

No entanto, esse incremento nos gastos com arrendamento pode ser fruto da expansão da produtividade de outros grãos. Nesta seção, descreve-se a metodologia estatística utilizada para testar a hipótese de que a evolução da produtividade do arroz é a principal responsável pelo aumento dos gastos com arrendamento nas áreas de produção do arroz irrigado no Rio Grande do Sul.

\subsection{Dados utilizados}

Para a realização deste trabalho, utilizou-se diversas bases de dados. Os valores sobre gastos com arrendamento foram extraídos dos Censos Agropecuários de 2006 e 2017, realizados pelo IBGE, ao passo que os dados de área semeada, quantidade produzida, rendimento médio da produção e valor da produção foram obtidos a partir da Produção Agrícola Municipal (PAM), também do IBGE. Os dados da PAM foram coletados para as culturas de arroz, milho e soja, com periodicidade anual, entre 2006 e 2018. Os dados referentes à cultura do milho e da soja foram necessários para serem utilizados como variáveis de controle na análise estatística realizada.

Tanto os dados dos Censos Agropecuários quanto os da PAM foram extraídos por meio do Sistema IBGE de Recuperação Automática (SIDRA), e foram manipulados com a utilização do software R. Embora os Censos disponham dos dados de produção das culturas, optou-se pelos dados da PAM, uma vez que os dados censitários possuem, em certas circunstâncias, limitações de informações que buscam preservar a identidade dos declarantes.

Dados provenientes da pesquisa de Produto Interno Bruto dos Municípios (PIB Munic), do IBGE, foram coletados para obtenção dos Produtos Internos Brutos municipais, bem como os Valores Adicionados Brutos a preços correntes da agropecuária, referentes ao período entre 2006 e 2017. E, mais uma vez, utilizou-se a Plataforma SIDRA para esse objetivo.

Os dados foram tratados em sua dimensão municipal e regional, correspondendo aos 141 municípios e às seis regiões orizícolas delimitadas pelo IRGA. A deflação dos dados monetários foi realizada utilizando-se o Índice Geral de Preços - Disponibilidade Interna (IGP-DI), produzido pela Fundação Getúlio Vargas (FGV), e pelo Índice de Preços por Atacado (IPA), produzido pelo Bereau of Labor Statistics dos EUA. Além desses dados, utilizou-se, também, os dados sobre preços do arroz em casca do IRGA ${ }^{[11]}$ e dos balanços de suprimentos de arroz produzidos pelo USDA e pela CONAB.

\subsection{Regiões produtoras de arroz no Rio Grande do Sul}

Embora o IBGE tenha estabelecido oficialmente a divisão dos estados brasileiros em macro, meso e microrregiões, o IRGA tem sua própria divisão regional quando se trata de produção de arroz. Essa subdivisão tem o objetivo de otimizar os processos administrativos do instituto no que diz respeito ao suporte à orizicultura estadual. Segundo o instituto, as regiões orizícolas do estado do Rio Grande do Sul são seis, conforme o descrito na Tabela 1.

Tabela 1. Número de municípios, área colhida de arroz e produtividade na safra 2018/2019 por região orizícola do estado do Rio Grande do Sul ${ }^{1,2}$

\begin{tabular}{|c|c|c|c|}
\hline \multirow[t]{2}{*}{ Região orizícola } & \multirow[t]{2}{*}{ Número de municípios } & Área colhida de arroz & Produtividade \\
\hline & & -------- ha --------- & -------" kg ha-1 -------- \\
\hline Fronteira Oeste & 17 & 284.985 & 7.669 \\
\hline Campanha & 13 & 139.985 & 7.132 \\
\hline Depressão Central & 33 & 132.519 & 7.256 \\
\hline Planície Costeira Interna & 32 & 138.655 & 7.342 \\
\hline Planície Costeira Externa & 33 & 112.774 & 7.112 \\
\hline Zona Sul & 13 & 155.619 & 8.198 \\
\hline Total & 141 & 964.537 & 7.508 \\
\hline
\end{tabular}

Fonte: Elaborado pelos autores, com base em IRGA ${ }^{[15]}$.

${ }^{1}$ Embora o IRGA ${ }^{[14]}$ afirme que os municípios integrantes das seis regiões orizícolas gaúchas sejam 142, a contagem na lista do anexo I da publicação apresenta apenas 141 municipios.

${ }^{2} 0$ município de Lavras do Sul é assistido por dois Núcleos de Assistência Técnica e Extensão (Nates). Enquanto o $20^{\circ}$ NATE é sediado em Dom Pedrito e contado na região da Campanha, $031^{\circ}$ é sediado em Caçapava do Sul e contado na região da Depressão Central. Neste trabalho, optou-se por contar Lavras do Sul como integrante da região da Depressão Central. 
A Figura 1 apresenta o posicionamento geográfico de cada uma das regiões orizícolas do estado e suas principais cidades. Ao norte do estado, representado em branco, não se presta à cultura do arroz irrigado. Cabe destacar que a produção de arroz nessas regiões beneficia-se da possibilidade da irrigação por inundação, processo que aumenta substancialmente a produtividade da cultura em relação àquela realizada em terrenos sem irrigação, o chamado arroz de terras altas, antigamente conhecido como arroz de sequeiro.

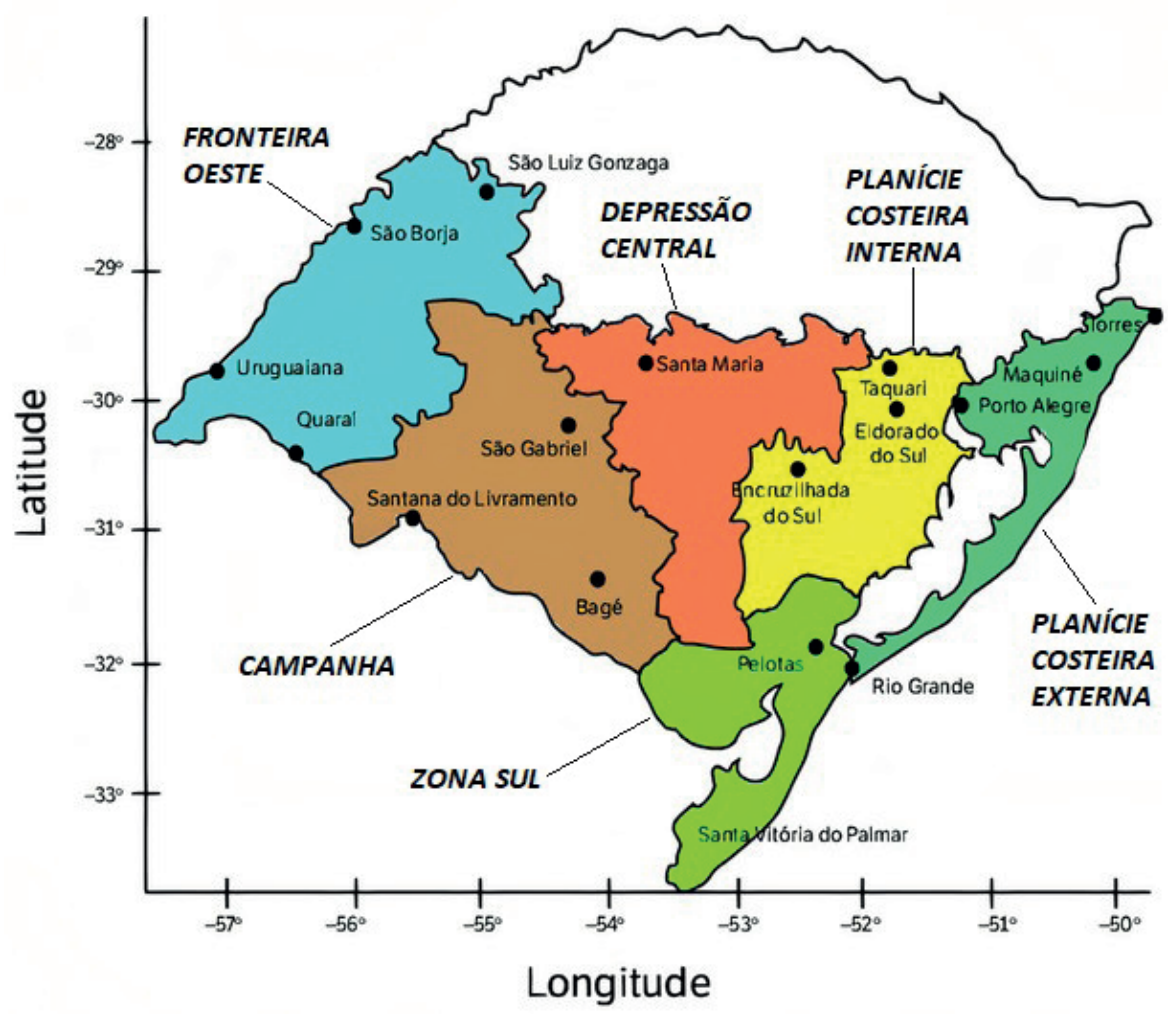

Figura 1. Localização geográfica das regiões orizícolas gaúchas Fonte: Klering et al. ${ }^{[16]}$

Comparando-se o ano safra 2005/2006 com 2016/2017, pode-se afirmar que, com oscilações, a produção tem tendência de crescimento em todas as regiões, embora tenha crescido mais na Zona Sul e na Planície Costeira Interna, e menos na Campanha e na Depressão Central, como apresentado na Figura 2, a seguir:

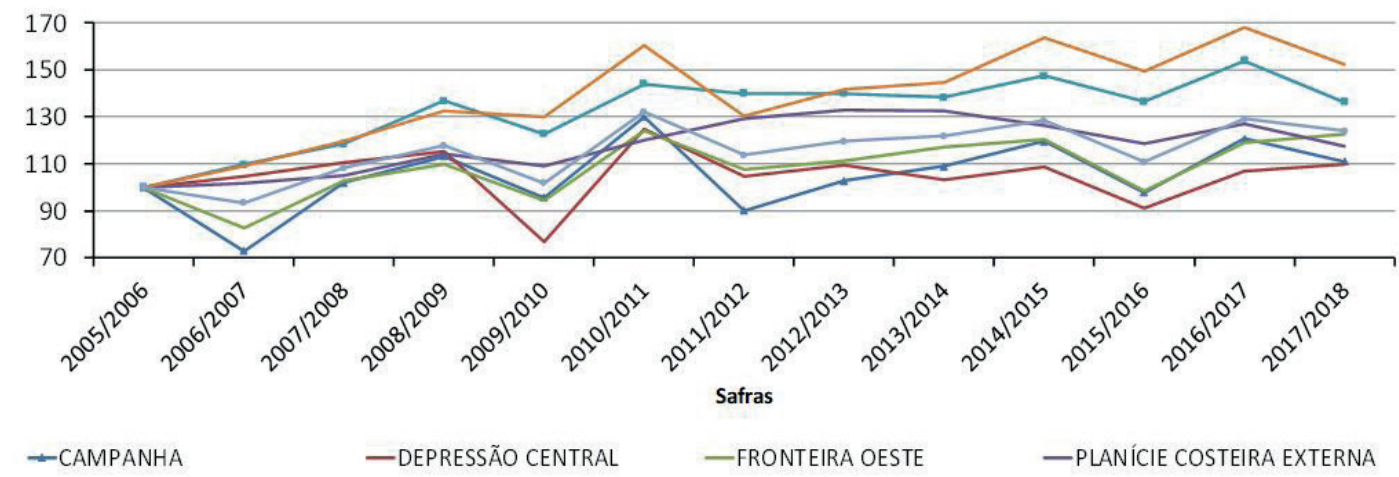

Figura 2. Evolução da produção de arroz nas regiões produtoras gaúchas em números índice (safra $2005 / 2006=100)$

Fonte: Elaborado pelos autores, com base na Pesquisa Agrícola Municipal, realizada pelo IBGE ${ }^{[17]}$ 
As áreas semeadas com arroz mostraram discrepância ainda maior entre as regiões, bem como as variações de produtividade, conforme Tabela 2.

Tabela 2. Variações nas áreas semeadas e na produtividade do arroz nas regiões orizícolas gaúchas, entre as safras 2005/2006 e 2016/2017

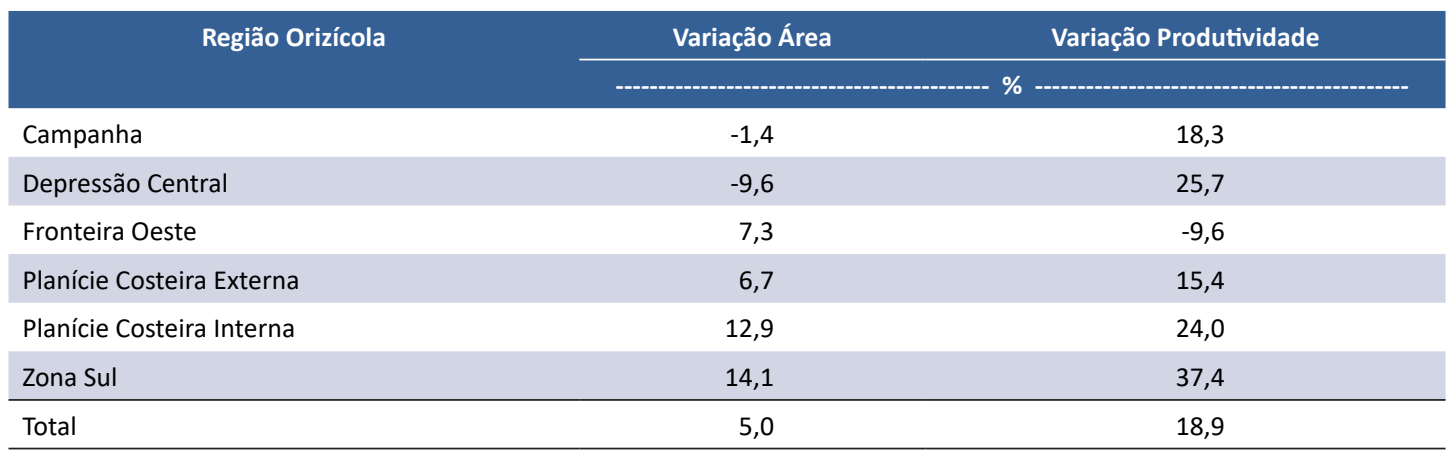

Fonte: Elaborado pelos autores, com base na Pesquisa Agrícola Municipal, realizada pelo IBGE ${ }^{[17]}$.

De acordo com os padrões de variações nas áreas de produção e de produtividade, pode-se, grosso modo, dividir as regiões orizícolas gaúchas em três grupos. O primeiro deles é formado pelas regiões da Campanha e da Depressão Central, apresenta redução de área semeada de arroz e crescimento na produtividade. Nessas regiões têm ocorrido concentração da produção justamente nas áreas mais produtivas, isto é, a produtividade vem crescendo em função do abandono de áreas menos produtivas para o arroz. O segundo grupo é formado pelas regiões da Planície Costeira Interna, da Planície Costeira Externa e pela Zona Sul. Nesse grupo, tanto a área plantada com arroz quanto a produtividade da cultura vêm crescendo.

Por fim, o terceiro grupo tem como único integrante a região da Fronteira Oeste. Essa região é a maior produtora de arroz do Rio Grande do Sul, produzindo cerca de $1 / 3$ do total de grãos do estado. No entanto, enquanto a produtividade apresenta tendência de queda, a área apresenta tendência de elevação. Esses efeitos contrapostos mantêm a participação da região na produção total, contudo expõe os produtores a riscos financeiros, pois, flutuações nos preços passam a atingi-los mais fortemente à medida que perdem produtividade.

De todo modo, vale observar que a produtividade na cultura do arroz irrigado teve aumento expressivo entre as safras 2005/2006 e 2016/2017. Fato semelhante também foi observado no que diz respeito à produtividade da soja e do milho, no que tange às regiões orizícolas gaúchas, como se pode observar na Tabela 3.

Tabela 3. Variações nas áreas semeadas e na produtividade da soja e do milho nas regiões orizícolas gaúchas, entre as safras 2005/2006 e 2016/2017

\begin{tabular}{|c|c|c|c|c|}
\hline \multirow{3}{*}{ Região Orizícola } & \multicolumn{2}{|c|}{ Variação Área } & \multicolumn{2}{|c|}{ Variação Produtividade } \\
\hline & Milho & Soja & Milho & Soja \\
\hline & ------ & --------- & ----- & ------- \\
\hline Campanha & $-32,4$ & 213,0 & 167,1 & 102,2 \\
\hline Depressão Central & $-43,8$ & 153,2 & 150,6 & 66,3 \\
\hline Fronteira Oeste & $-20,2$ & 39,9 & 121,5 & 174,4 \\
\hline Planície Costeira Externa & $-37,5$ & 617,5 & 62,1 & 344,3 \\
\hline Planície Costeira Interna & $-34,2$ & 253,6 & 68,2 & 68,0 \\
\hline Zona Sul & $-46,3$ & 420,0 & 108,4 & 76,8 \\
\hline Total & $-36,3$ & 138,5 & 104,3 & 100,6 \\
\hline
\end{tabular}

Fonte: Elaborado pelos autores, com base na Pesquisa Agrícola Municipal, realizada pelo IBGE ${ }^{[17]}$.

É possível observar que a produtividade das culturas de milho e soja teve crescimento ainda mais acentuado que a do arroz e com respeito às áreas, elevação acentuada na área destinada ao plantio de soja e retração nas áreas destinadas à cultura do milho. É importante, também, observar que a expansão da soja dá-se em detrimento das áreas anteriormente cultivadas com milho, 
processo que não tem paralelo na cultura do arroz, uma vez que houve crescimento de $5 \%$ em sua área (ver Tabela 2). Esse ponto é essencial para o entendimento dos resultados estatístico que foram obtidos e pode ser explicado pelas peculiaridades agronômicas, topológicas e hidrológicas das áreas destinadas à cultura orizícola.

\subsection{Evolução da demanda por arroz no Brasil}

A evolução da demanda nacional por arroz não acompanhou o ritmo do crescimento da produtividade na produção desse grão. Muitos são os fatores apontados para a estagnação dessa demanda.

A elevação da renda, especialmente nos extratos mais pobres, associada à elasticidade negativa do arroz em relação à renda, teve efeito redutor sobre a demanda, segundo Queiroz e Coelho ${ }^{[18]}$. Além disso, segundo Bezerra et al. ${ }^{[19]}$, a tendência de crescimento na alimentação fora do domicílio também reduz o consumo de arroz em termos per capita. Realmente, a apreciação da Figura 3 demonstra claramente a redução do consumo total de arroz no Brasil, bem como dos valores do consumo per capita.

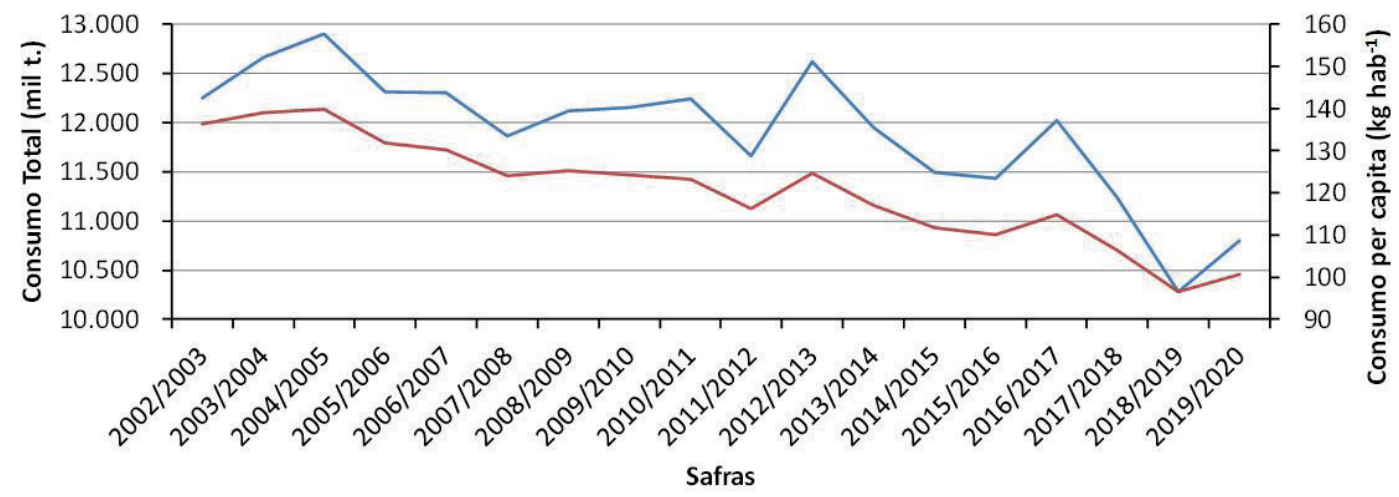

Figura 3. Evolução do consumo total e per capita de arroz no Brasil Fonte: Elaborado pelos autores, com base em CONAB $^{[20]}$ e IBGE ${ }^{[17]}$.

Entre as safras 2002/2003 e 2019/2020, a taxa média de retração anual do consumo total de arroz foi de $0,7 \%$, o que resultou em declínio de $11,8 \%$, no período. Já no caso do consumo per capita, a taxa média de declínio anual foi de $1,8 \%$ e a redução acumulada no mesmo período de $26,3 \%$.

\subsection{Preços do arroz a longo prazo}

O aumento potencial de oferta, causado pelo aumento da produtividade na cultura orizícola, associado à estagnação da demanda pelo produto tem gerado, ao longo dos anos, pressão de baixa nos preços do arroz, a qual reduziu - em termos reais - o valor do produto em $75,1 \%$, entre 1975 e $2019^{[11]}$. No entanto, quando os preços desses dois períodos são comparados em dólares americanos, observa-se elevação de 12,3\%. A Figura 4 mostra graficamente essa evolução:

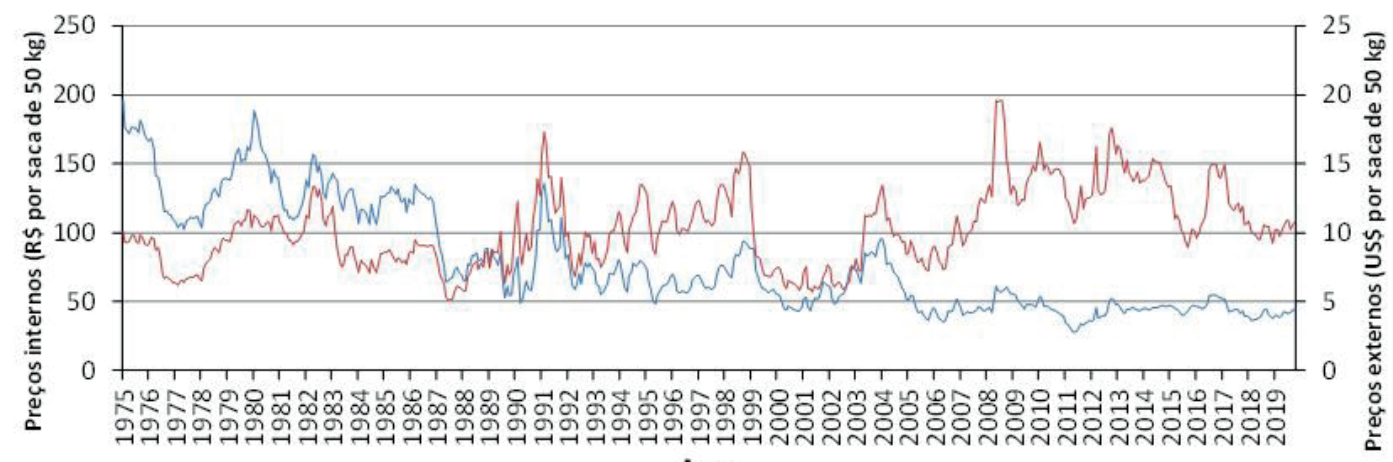

Anos

Figura 4. Evolução dos preços internos e externos do arroz em casca - saca de $50 \mathrm{~kg}$. Preços internos deflacionados pelo IGPM-DI e preços em dólar deflacionados pelo IPA dos Estados Unidos (Base: outubro de 2019)

Fonte: Elaborado pelos autores, com base em IRGA ${ }^{[11]}$. 
Essa tendência discrepante entre os preços internos e os externos indica duas características do agronegócio do arroz no Brasil. Em primeiro lugar, o relativo isolamento da produção de arroz brasileira que não consegue beneficiar-se da dinâmica mais favorável dos preços internacionais ${ }^{3}$. Em segundo lugar, a existência de pressão interna para declínio dos preços, essa baixa secular que tem sido observada no mercado brasileiro e que não pode ser explicada por fatores de origem internacional.

\subsection{Despesas com arrendamentos}

As despesas com arrendamentos cresceram significativamente nas áreas orizícolas gaúchas mesmo quando se consideram os valores deflacionados -, mais que dobrando de valor e atingindo o patamar de R\$996 milhões, no decorrer da safra 2016/2017. Esse crescimento revela o progresso da agropecuária brasileira e, particularmente, da gaúcha. A Tabela 4 apresenta as evoluções dos montantes pagos a título de arrendamento, por região orizícola, e suas respectivas variações.

Tabela 4. Despesas reais* com arrendamentos nas regiões orizícolas gaúchas, entre as safras 2005/2006 e 2016/2017

\begin{tabular}{lccc}
\multirow{2}{*}{ Região Orizícola } & \multicolumn{2}{c}{ Despesas com arrendamentos** } & \multirow{2}{*}{ Variação } \\
\cline { 2 - 3 } & Safra 2005/2006 & Safra 2016/2017 & 186,9 \\
\cline { 2 - 3 } Campanha & 67.729 & 194.297 & 100,0 \\
\hline Depressão Central & 121.077 & 242.143 & 100,6 \\
\hline Fronteira Oeste & 118.359 & 237.430 & 85,4 \\
\hline Planície Costeira Externa & 31.563 & 58.530 & 200,2 \\
\hline Planície Costeira Interna & 51.080 & 153.365 & 203,7 \\
\hline Zona Sul & 36.205 & 109.971 & 133,7 \\
\hline Total & 426.012 & 995.736 & 2 \\
\hline
\end{tabular}

Notas: *Valores deflacionados pelo IGPM-DI (Base: outubro de 2019). **Valores em mil.

Fonte: Elaborado pelo autor, com base em dados dos Censos Agropecuários de 2006 e 2017 [12], [17].

Um exercício preliminar interessante para averiguar-se a influência do aumento de produtividade das diversas culturas de grãos sobre o crescimento dos gastos com arrendamentos é o cálculo da correlação entre essas variáveis, tomadas regionalmente. Esse exercício foi realizado e os resultados estão dispostos na seção Resultados e Discussão, deste artigo.

\subsection{Avaliação dos fatores determinantes aos gastos com arrendamentos}

O primeiro exercício realizado com o intuito de se avaliar os fatores que impactam os gastos com arrendamentos, especificamente nas regiões produtoras de arroz irrigado do Rio Grande do Sul, foi a análise de correlação entre a variação das despesas com arrendamentos e as variações da produtividade da cultura de arroz irrigado, soja e milho, respectivamente, ambas em escala municipal. Nesse exercício, considerou-se os dados referentes aos municípios das regiões orizícolas.

Em seguida, realizou-se regressões lineares, a fim de se mensurar o impacto do crescimento da produtividade física das lavouras temporárias sobre os preços de arrendamento nas regiões orizícolas gaúchas.

Com esse intento, estimou-se, primeiramente, a Equação 1:

$$
\ln \left(\operatorname{VDAr}_{\mathrm{i}}\right)=b_{0}+b_{1} \ln \left(\mathrm{VPFA}_{\mathrm{i}}\right)+b_{2} \ln \left(\mathrm{VPFM}_{\mathrm{i}}\right)+b_{3} \ln \left(\mathrm{VPFS}_{\mathrm{i}}\right)+e_{\mathrm{i}}
$$

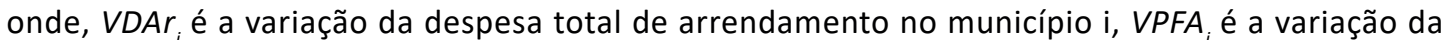
produtividade física da cultura do arroz no município i, $V P F M_{i}$ é a variação da produtividade física da cultura do milho no município i, $V P F S_{i}$ é a variação da produtividade física da cultura da soja no município i. Todas essas variações foram calculadas entre os anos de 2006 e 2017. Os parâmetros $b$, de 0 a 3 , são os valores estimados, $e_{i}$ representa os erros aleatórios, normalmente distribuídos, associados ao município i, e In é o operador de logaritmo natural. 
Uma segunda regressão foi realizada, de acordo com a Equação 2, descrita a seguir, na qual foi acrescentada a variável $V V A_{i}$, que representa a variação no valor adicionado agropecuário no município i, na tentativa de se captar o efeito do crescimento agropecuário do município sobre os dispêndios locais com arrendamento.

$$
\ln \left(\operatorname{VDAr}_{\mathrm{i}}\right)=b_{0}+b_{1} \ln \left(\mathrm{VPFA}_{\mathrm{i}}\right)+b_{2} \ln \left(\mathrm{VPFM}_{\mathrm{i}}\right)+b_{3} \ln \left(\mathrm{VPFS}_{\mathrm{i}}\right)+b_{4} \ln \left(\mathrm{VVA}_{\mathrm{i}}\right)+e_{\mathrm{i}}
$$

Por fim, acrescentou-se variáveis "dummies" para cada uma das regiões produtoras e um terceiro modelo foi estimado, conforme a Equação 3:

$$
\begin{gathered}
\ln \left(\operatorname{VDAr}_{\mathrm{i}}\right)=b_{0}+b_{1} \ln \left(\mathrm{VPFA}_{\mathrm{i}}\right)+b_{2} \ln \left(\mathrm{VPFM}_{\mathrm{i}}\right)+b_{3} \ln \left(\mathrm{VPFS}_{\mathrm{i}}\right)+b_{4} \ln \left(\mathrm{VVA}_{\mathrm{i}}\right)+b_{\mathrm{ch}} d_{\mathrm{ch}} \\
+b_{\mathrm{DC}} d_{\mathrm{DC}}+b_{\mathrm{FO}} d_{\mathrm{FO}}+b_{\mathrm{zS}} d_{\mathrm{zS}}+b_{\mathrm{PE}} d_{\mathrm{PE}}+\mathrm{e}_{\mathrm{i}}
\end{gathered}
$$

As variáveis $d_{C H i^{\prime}} d_{D C i^{\prime}} d_{F O i^{\prime}}, d_{Z S i}$ e $d_{P E i}$ são variáveis binárias, que assumem valor 1 caso a observação se refira a município integrante da região especificada, e 0 em caso contrário. As abreviaturas $C H$, $D C, F O, Z S, P E$ referem-se, respectivamente, às regiões da Campanha, Depressão Central, Fronteira Oeste, Zona Sul e Planície Costeira Externa. A região da Planície Costeira Interna foi utilizada como referência e as variáveis b, associadas às variáveis "dummies", são os parâmetros a serem estimados e medem o efeito das regiões sobre a variação dos preços de arrendamento.

Em adição à estimativa dos parâmetros, efetuou-se testes auxiliares de aderência, robustez e significância em relação à equação estimada e aos parâmetros obtidos.

\section{Resultados e Discussão}

\subsection{Produtividade e gastos com arrendamento}

Um dos pontos centrais do argumento elaborado neste trabalho é que o crescimento da produtividade na cultura do arroz irrigado não foi acompanhado por incremento equivalente na demanda interna pelo produto. Isso acarreta redução nos preços, além do que seria esperado apenas pelo aumento da produtividade.

Por outro lado, o crescimento diferencial da produtividade do arroz, nos diversos municípios integrantes da região produtora gaúcha, estimulou o crescimento dos gastos com arrendamento.

Os resultados obtidos neste estudo indicam que o crescimento da produtividade do arroz, e não o de outras culturas temporárias como a soja ou o milho, foi o responsável pelo incremento nesses gastos com arrendamentos.

Essa hipótese não é descartada pelo mapeamento das correlações entre as variações da produtividade das principais culturas de grãos da região - arroz, soja e milho -, e as variações dos gastos com arrendamentos em cada uma das regiões orizícolas gaúchas, entre as safras 2005/2006 e 2016/2017, conforme é mostrado na Tabela 5

\begin{tabular}{|c|c|c|c|c|}
\hline \multirow{3}{*}{ Região Orizícola } & \multirow{2}{*}{$\begin{array}{c}\text { Variação das despesas com } \\
\text { arrendamentos }\end{array}$} & \multicolumn{3}{|c|}{ Variações na produtividade } \\
\hline & & Arroz & Milho & Soja \\
\hline & ----------- & $-\cdots$ & 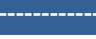 & ------ \\
\hline Campanha & 186,9 & 18,32 & 167,1 & 102,2 \\
\hline Depressão Central & 100,0 & 25,72 & 150,6 & 66,3 \\
\hline Fronteira Oeste & 100,6 & $-9,62$ & 121,5 & 174,4 \\
\hline Planície Costeira Externa & 85,4 & 15,41 & 62,1 & 344,3 \\
\hline Planície Costeira Interna & 200,2 & 24,02 & 68,2 & 68,0 \\
\hline Zona Sul & 203,7 & 37,44 & 108,4 & 76,8 \\
\hline $\begin{array}{l}\text { Correlação com as despesas com } \\
\text { arrendamentos }\end{array}$ & 1,000 & 0,568 & 0,041 & $-0,644$ \\
\hline
\end{tabular}

Tabela 5. Correlações entre as variações nas despesas com arrendamentos nas regiões orizícolas gaúchas e na produtividade das principais culturas de grãos, entre as safras 2005/2006 e 2016/2017

Fonte: Elaborado pelos autores, com base nos Censos Agropecuários de 2006 e $2017^{[12],[17]}$ e resultados da pesquisa. 
A correlação positiva entre a variação com despesas de arrendamento e a variação da produtividade do arroz implica sinalização importante sobre o fenômeno estudado. Embora as variações na produtividade do milho e da soja superem àquela observada para o arroz, suas correlações com o crescimento dos gastos com arrendamento são estatisticamente nulas, no caso do milho, e negativa, no caso da soja.

Esse é um indicativo importante de que o principal condutor dos aumentos de gastos com arrendamento nessas regiões seja a elevação da produtividade orizícola, a despeito de seu crescimento módico em relação ao aumento da produtividade dos outros grãos.

\subsection{Regressões}

Para testar a influência dos ganhos de produtividade sobre os preços de arrendamento de terras nas regiões orizícolas do Rio Grande do Sul, realizou-se regressões. Em todos os modelos testados, a variável explicada é a variação no total das despesas de arrendamento no município, entre 2006 e 2017.

Na primeira delas, a variável endógena é regredida, contra a variação da produtividade física na cultura do arroz (VPFA), contra a variação da produtividade física na cultura do milho (VPFM), contra a variação da produtividade física na cultura da soja (VPFS). Os resultados dessa regressão são apresentados na Tabela 6 (Regressão 1).

Tabela 6. Resultados das regressões - variável explicada: variação na despesa municipal total com arrendamentos; variáveis explicativas: variação na produtividade física do arroz, do milho e da soja nos empreendimentos no município, variação no valor agregado agropecuário municipal, entre 2006 e 2017

\begin{tabular}{|c|c|c|c|}
\hline Parâmetro & Regressão 1 & Regressão 2 & Regressão 3 \\
\hline \multirow{10}{*}{ Intercepto } & 0,9732 & 1,1892 & 3,05775 \\
\hline & 1,018 & 1,021 & $1,239 * *$ \\
\hline & 0,3540 & 0,3356 & 0,29756 \\
\hline & $0,137 * *$ & $0,136 * *$ & $0,148 * *$ \\
\hline & 0,2242 & 0,1879 & 0,09378 \\
\hline & 0,158 & 0,159 & 0,160 \\
\hline & 0,1984 & $-0,5752$ & $-0,81162$ \\
\hline & $0,082 * *$ & 0,493 & 0,530 \\
\hline & & 0,8156 & 0,91555 \\
\hline & & 0,513 & $0,548^{*}$ \\
\hline \multirow{2}{*}{$d_{C H}$} & & & $-0,09278$ \\
\hline & & & 0,816 \\
\hline \multirow{2}{*}{$d_{D C}$} & & & $-0,26696$ \\
\hline & & & 0,636 \\
\hline \multirow{2}{*}{$d_{F O}$} & & & $-0,53882$ \\
\hline & & & 0,743 \\
\hline \multirow{2}{*}{$d_{z s}$} & & & $-1,38873$ \\
\hline & & & $0,796^{*}$ \\
\hline \multirow{2}{*}{$d_{P E}$} & & & $-1,72970$ \\
\hline & & & $0,670 * *$ \\
\hline Número de Observações & 141 & 141 & 141 \\
\hline Graus de Liberdade & 137 & 136 & 131 \\
\hline Coeficiente de Determinação $\mathrm{R}^{2}$ & 0,1172 & 0,1348 & 0,1926 \\
\hline $\begin{array}{l}\text { Coeficiente de Determinação } \mathrm{R}^{2} \\
\text { Ajustado }\end{array}$ & 0,0962 & 0,1071 & 0,1321 \\
\hline Estatística-F & 5,577 & 4,867 & 3,181 \\
\hline Valor-p & 0,001263 & 0,001110 & 0,001754 \\
\hline
\end{tabular}

Notas: ${ }^{* *}$ significativo a $5 \% ;{ }^{*}$ significativo a $10 \%$.

Fonte: Elaborado pelos autores. 
Na Regressão 1, cujos resultados estão descritos na segunda coluna da Tabela 6, as variações na produtividade física do arroz e da soja apresentaram significância a 5\%, sendo que a elasticidade de resposta das despesas de arrendamento é maior no caso da primeira. A variação da produtividade do milho não apresentou impacto significante sobre a variável explicada.

Na Regressão 2, cujos resultados estão descritos na terceira coluna da Tabela 6, acrescentou-se a variação do valor agregado agrícola municipal (VVA) como variável explicativa. Nesse caso, a única variável a apresentar significância ${ }^{4}$ foi a variação da produtividade do arroz. A perda de significância da variação da produtividade da soja, por sua vez, se deve a possível multicolinearidade entre a variação do valor agregado agropecuário do município e a variação na produtividade física da soja.

Por fim, na Regressão 3, cujos resultados estão descritos na quarta coluna da Tabela 6, foram inseridas, além das variáveis já utilizadas na Regressão 2, uma série de variáveis "dummy", na tentativa de capitar-se os efeitos regionais. Essas variáveis são as seguintes: $d_{C H}$ que assume valor 1 caso o registro se refira a algum município da região da Campanha, e 0 em caso contrário. As variáveis $d_{D C^{\prime}} d_{F O}, d_{Z S}$ e $d_{P E}$ seguem o mesmo padrão, mas para as regiões da Depressão Central, Fronteira Oeste, Zona Sul e Planície Costeira Externa, respectivamente. A sexta região orizícola, a Planície Costeira Interna, não possui variável "dummy" a ela associada por tratar-se de região de referência, com as quais as demais são comparadas nesse exercício.

Na Regressão 3 (Tabela 6), novamente VPFA apresentou significância a 5\% e VVA a 10\%. Entre as variáveis "dummy" regionais, somente aquelas que se referem à Planície Costeira Externa e à Zona Sul apresentaram significância a $5 \%$ e $10 \%$, respectivamente. Isso sugere que o padrão de influência das variáveis explicativas não binárias difere somente nessas duas regiões. Nelas, os resultados indicam que ocorre menor efeito das variações de produtividades e do valor agregado agropecuário sobre o aumento nas despesas com arrendamentos.

A análise do conjunto de regressões permitiu algumas conclusões. Sob âmbito técnico é possível observar que todos os exercícios realizados têm significância global, fato que pode ser atestado pelos resultados dos Testes-F e seus respectivos Valores-p (Tabela 6).

Em termos de robustez dos resultados, a variável VPFA mostrou-se significante em todas as regressões realizadas. Isso indica que, de fato, a variação na produtividade física da cultura do arroz é o principal fator determinante no aumento das despesas com arrendamento nas regiões orizícolas gaúchas.

Sob a perspectiva de gestão do agronegócio, e considerando-se que a produtividade deve continuar aumentando e que a demanda interna não dá sinais de recuperação, a queda de preços do produto deverá continuar a longo prazo. Nesse processo, os arrendamentos das regiões mais produtivas deverão continuar a crescer em contraposição àqueles das regiões nas quais a produtividade avança mais lentamente.

Nesse cenário, seria vantajoso aos agricultores negociarem contratos de parceria nas regiões de menor crescimento na produtividade, além de continuarem com contratos de arrendamento em regiões de crescimento rápido.

\section{Conclusão}

Este estudo debruçou-se sobre a aparente dicotomia entre a elevação dos gastos com arrendamentos nas regiões orizícolas gaúchas e as dificuldades crescentes enfrentadas pelos produtores no mercado interno de arroz. Os resultados encontrados mostram que a demanda pelo produto vem retraindo-se no mercado interno e que a oferta potencial tem crescido em função do aumento de produtividade, o que deprime, a longo prazo, os preços internos. Mas, como o crescimento dessa produtividade não é uniforme, detectou-se que os gastos com arrendamento são primariamente determinados pela elevação da produtividade do arroz e que, embora a produtividade dos principais grãos alternativos (soja e milho) cresceu mais fortemente no período entre os Censos Agrícolas de 2006 e 2017, tais incrementos não apresentaram impacto na elevação dos gastos com arrendamento na região estudada.

Sob a perspectiva de gestão do agronegócio, este estudo leva à prescrição de que, dada a estagnação secular da demanda por arroz no mercado interno e dado o crescimento significativo da produtividade, os produtores devem concentrar esforços na exportação do produto.

Adicionalmente, em função do crescimento diferencial da produtividade na região orizícola

${ }^{4}$ Significância a $5 \%$. 
gaúcha, o produtor deve selecionar cuidadosamente o contrato a ser celebrado com os donos das propriedades: parceria para as regiões com menor crescimento da produtividade e arrendamento nas regiões de crescimento mais acentuado.

Contribuições dos autores: Todos os autores contribuíram no Design, Coleta de Dados, Análise de Dados, Definição de Metodologia, Redação e Edição.

Como citar: Miranda, R.B, Dalchiavon, F.C. Produtividade, demanda e gasto com arrendamentos na orizicultura gaúcha. Quaestum. 2022; (3): e26750574

\section{Referências}

[1] Beskow P.R. A formação da economia arrozeira do Rio Grande do Sul. Ens. FEE. 1984; 4(2): 55-84.

[2] Oliveira T.E.; Freitas D.S.; Gianezini M.; Ruviaro C.F.; Zago D.; Mércio T.Z. et al. Agricultural land use change in the Brazilian Pampa Biome: The reduction of natural grasslands. Land Use Policy. 2017; 63: 394-400.

[3] Herrlein Jr, R. A transição capitalista no Rio Grande do Sul, 1889-1930: uma nova interpretação. Econ Soc. 2004; 13(1): 175-207.

[4] Instituto Rio Grandense do Arroz (IRGA). Área e produção de arroz. Porto Alegre: IRGA; 2019. Disponível em: <https:// irga-admin.rs.gov.br/upload/arquivos/201909/19141756-producao-rs-x-br.pdf>.

[5] Companhia Nacional de Abastecimento (CONAB). Evolução dos custos de produção de arroz no Brasil. Compêndio de Estudos Conab, vol. 4. Brasília: CONAB; 2016.

[6] Azeredo M.S.L.; Dalchiavon F.C. Diagnóstico das lavouras de arroz do Rio Grande do Sul: Safras 2004/2005 x $2014 / 2015$ Rev. iPecege. 2017; 3(2):86-108.

[7] Zanin V.; Bacchi M.R.P. Análise da margem de comercialização do arroz gaúcho no mercado de São Paulo, após o Plano Real. Ens. FEE. 2016; 36(4): 843-868.

[8] Marion Filho P.J.; Einloft N.E. A competitividade do arroz irrigado brasileiro no Mercosul. Organ. Rurais Agroind. 2008; 10(1): 1-22.

[9] Souza A.R.L.; Revillion J.P.P.; Waquil P.D.; Belarmino L.C.; Lanfranco B.A. Economic and accounting evaluation of rice milled production chains in Rio Grande do Sul (Brazil) and Uruguay with application of the Policy Analysis Matrix. Ciênc. rural. 2017; 47(4): 1-7.

[10] United States Department of Agriculture (USDA). Grain: World Markets and Trade. Washington: USDA; 2020. Disponível em: <https://apps.fas.usda.gov/psdonline/circulars/grain.pdf>.

[11] Instituto Rio Grandense do Arroz (IRGA). Série histórica de preços de arroz em casca. Porto Alegre: IRGA; 2019. Disponível em: <https://irga-admin.rs.gov.br/upload/arquivos /201912/19135628-casca-out-2019.pdf>.

[12] Instituto Brasileiro de Geografia e Estatística (IBGE). Censo agropecuário 2006: Brasil, Grandes Regiões e Unidades da Federação. Rio de Janeiro: IBGE; 2006.

[13] Instituto Brasileiro de Geografia e Estatística (IBGE). Censo agropecuário: resultados definitivos 2017. Rio de Janeiro: IBGE; 2019.

[14] Instituto Rio Grandense do Arroz (IRGA). Censo da lavoura de arroz irrigado do Rio Grande do Sul - safra 2004/5. Porto Alegre: IRGA; 2006.

[15] Instituto Rio Grandense do Arroz (IRGA). Boletim de resultados da lavoura - safra 2018/19 - Arroz irrigado e soja em rotação. Porto Alegre: IRGA; 2019. Disponível em: <https://irga.rs.gov.br/irga-divulga-boletim-de-resultados-dasafra-2018-2019>.

[16] Klering E.V.; Fontana D.C.; Roglio V.S.; Alves R.C.M.; Berlato M.A. Modelo agrometeorológico-espectral para estimativa da produtividade de grãos de arroz irrigado no Rio Grande do Sul. Bragantia. 2016; 75(2): 247-256.

[17] Instituto Brasileiro de Geografia e Estatística (IBGE). Produção Agrícola Municipal: Culturas temporárias e permanentes. Rio de Janeiro: IBGE; 2018.

[18] Queiroz P.W.V.; Coelho A.B. Alimentação fora de casa: uma investigação sobre os determinantes da decisão de consumo dos domicílios brasileiros. Análise Econômica. 2017; 67: 67-104.

[19] Bezerra I.N.; Souza A.M.; Pereira R.A.; Sichieri R. Consumo de alimentos fora do domicílio no Brasil. ver. Saúde Públ. 2013; 47(1): 200-2011.

[20] Companhia Nacional de Abastecimento (CONAB). Acompanhamento da safra brasileira de grãos. Observatório Agrícola, vol. 7. Brasília: CONAB; 2020. 